\title{
DNA barcode identification of lichen-forming fungal species in the Rhizoplaca melanophthalma species-complex (Lecanorales, Lecanoraceae), including five new species
}

\author{
Steven D. Leavitt ${ }^{1,2}$, Fernando Fernández-Mendoza ${ }^{3,4}$, \\ Sergio Pérez-Ortega ${ }^{5}$, Mohammad Sohrabi ${ }^{6}$, Pradeep K. Divakar ${ }^{7}$, \\ H. Thorsten Lumbsch', Larry L. St. Clair ${ }^{2}$
}

I Department of Botany, Field Museum of Natural History, 1400 S. Lake Shore Drive, Chicago, IL 606052496, USA 2 Department of Biology and M. L. Bean Life Science Museum, Brigham Young University, Provo, UT 84602, USA 3 Department of Botany and Molecular Evolution, Senckenberg Research Institute, Senckenberganlage 25, D-60325 Frankfurt am Main, Germany 4 Biodiversity and Climate Research Center, Senckenberganlage 25, D-60325 Frankfurt am Main, Germany 5 Departamento de Biologia Ambiental, Museo Nacional de Ciencias Naturales (CSiC), C/ Serrano 115-dpdo., E-28006, Madrid, Spain 6 Iranian Research Organization for Science and Technology (IROST), 15815-115, Tehran, Iran 7 Departamento de Biologia Vegetal II, Facultad de Farmacia, Universidad Complutense de Madrid, Madrid E-28040, Spain

Corresponding author: Steven D. Leavitt (sleavitt@fieldmuseum.org)

Academic editor: I. Schmitt | Received 13 December 2012 | Accepted 17 April 2013 | Published 9 May 2013

Citation: Leavitt SD, Fernández-Mendoza F, Pérez-Ortega S, Sohrabi M, Divakar PK, Lumbsch TH, St. Clair LLS (2013) DNA barcode identification of lichen-forming fungal species in the Rhizoplaca melanophthalma species-complex (Lecanorales, Lecanoraceae), including five new species. MycoKeys 7: 1-22. doi: 10.3897/mycokeys.7.4508

\begin{abstract}
Recent studies using sequence data from multiple loci and coalescent-based species delimitation have revealed several species-level lineages within the phenotypically circumscribed taxon Rhizoplaca melanophthalma sensu lato. Here, we formally describe five new species within this group, $R$. occulta, $R$. parilis, $R$. polymorpha, R. porterii, and R. shushanii, using support from the coalescent-based species delimitation method implemented in the program Bayesian Phylogenetics and Phylogeography (BPP) as the diagnostic feature distinguishing new species. We provide a reference DNA sequence database using the ITS marker as a DNA barcode for identifying species within this complex. We also assessed intraspecific genetic distances within the six $R$. melanophthalma sensu lato species. While intraspecific genetic distances within the five new species were less than or equal to the lowest interspecific pairwise comparison values, an overlap in genetic distances within the $R$. melanophthalma sensu stricto clade suggests the potential for additional
\end{abstract}

Copyright Steven D. Leavitt et al. This is an open access article distributed under the terms of the Creative Commons Attribution License 3.0 (CC-BY), which permits unrestricted use, distribution, and reproduction in any medium, provided the original author and source are credited. 
phenotypically cryptic lineages within this broadly distributed lineage. Overall, our results demonstrate the potential for accurately identifying species within the $R$. melanophthalma group by using molecularbased identification methods.

\section{Key words}

Bio-monitoring, BPP, coalescence, cosmopolitan distribution, cryptic species, molecular identification, symbiosis

\section{Introduction}

The lichen symbiosis has been highly successful with more than 18,000 currently accepted species of lichen-forming fungi (Feuerer and Hawksworth 2007) and an estimated diversity of more than 28,000 species (Lücking et al. 2009). However, robust species delimitations and accurate identification of lichenized fungal species remains challenging (reviewed in Crespo and Perez-Ortega 2009; Crespo and Lumbsch 2010; Printzen 2010; Lumbsch and Leavitt 2011). In many cases, characters used for identification may be subtle or difficult to discern, diagnostic morphological and chemical characters may be lacking in juvenile or fragmentary samples, and the traditional phenotype-based approach to species recognition in lichenized fungi has been shown in some cases to substantially misrepresent diversity (e.g. Taylor et al. 2000; Divakar et al. 2010a; Kelly et al. 2011; Leavitt et al. 2011a; Leavitt et al. 2011b; Molina et al. 2011a; Schmull et al. 2011; Pino-Bodas et al. 2012). As in other groups of fungi, molecular data have also revolutionized our understanding of evolution and species delimitation in lichenized fungi (Crespo and Perez-Ortega 2009; Crespo and Lumbsch 2010; Printzen 2010; Lumbsch and Leavitt 2011). Furthermore, molecular-based identification methods now provide an accessory approach for specimen identification (Seifert 2009; Begerow et al. 2010; Del-Prado et al. 2010; Kelly et al. 2011; Schoch et al. 2012).

Using DNA barcoding, a reference DNA sequence database generated from expertly identified specimens can provide an effective alternative to phenotype-based identification of lichen-forming fungal species (Kelly et al. 2011; Schoch et al. 2012). However, the practicality of DNA barcoding as a major tool for identification of lichenized fungi is largely dependent on the development of high-quality sequence databases that are thoroughly curated by taxonomists and systematists (Begerow et al. 2010; Orock et al. 2012). Previous studies have demonstrated that a high proportion of lichen-forming fungal species can be correctly identified by comparing sequence similarity using BLAST-based identification from fragments of the internal transcribed spacer region of the nuclear ribosomal RNA cistron (ITS: ITS1-5.8S-ITS2) against custom databases (Kelly et al. 2011; Schoch et al. 2012). These results highlight the potential utility of DNA-based identification as a valuable tool in lichen systematics research. Furthermore, the ITS region was recently proposed for adoption by the Consortium for the Barcode of Life as the first fungal barcode marker (Schoch et al. 2012). However, its accuracy is largely dependent on the taxonomic knowledge and 

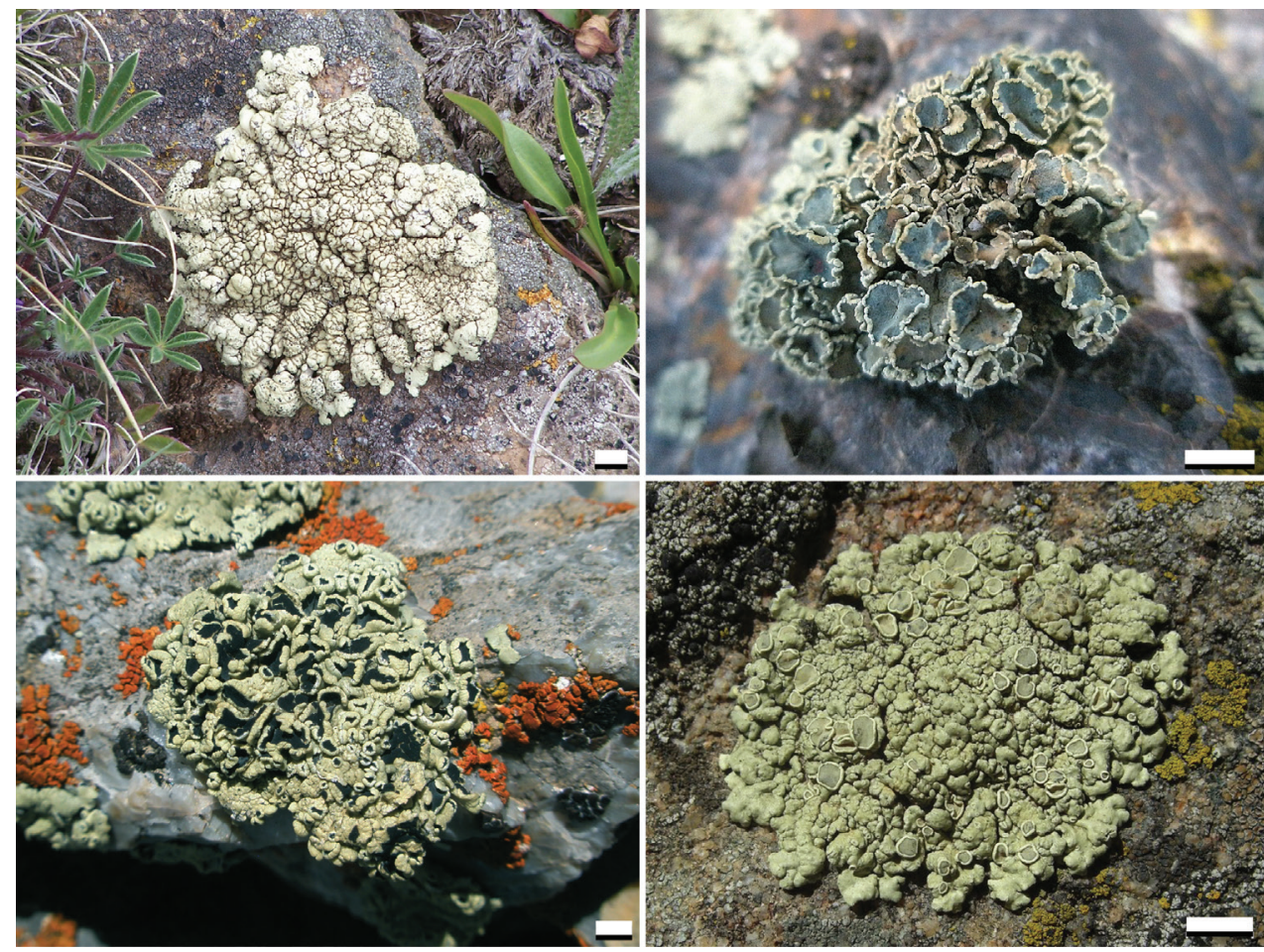

Figure I. Variation in morphology and habit within Rhizoplaca melanophthalma sensu lato. Scale bar $=5 \mathrm{~mm}$.

the sample coverage of the group (Roe et al. 2010; Kelly et al. 2011; Kiss 2012; Orock et al. 2012; Schoch et al. 2012).

Rhizoplaca Zopf, as currently circumscribed, is a morphologically diverse, polyphyletic genus (Arup and Grube 2000) represented by ca. 19 lichen-forming fungal species (Index Fungorum: http://www.indexfungorum.org/). Within the past decade a number of studies have indicated that traditional phenotype-based species circumscriptions fail to recognize multiple species-level lineages within this genus (Zhou et al. 2006; Leavitt et al. 2011a). The Rhizoplaca melanophthalma species-complex (sensu Leavitt et al. 2011a) includes a morphologically diverse assemblage of species, including individuals ranging from placodioid crustose and umbilicate forms, to completely vagrant, or obligatory unattached forms. Substantial chemical variation has been identified within this group, including at least four chemotypes within $R$. melanophthalma sensu lato (s.1.) (McCune 1987; Ryan 2001); and eight previously unrecognized extrolites recently identified from specimens within this complex (Leavitt et al. 2011a).

Within R. melanophthalma s. 1. (Fig. 1), Leavitt et al. (2011a) circumscribed six 'candidate' species that were supported using multiple lines of evidence from molecular sequence data, including: fixed nucleotide characters, genealogical exclusivity, Bayesian population clustering, and the coalescent-based species delimitation program Bayesian Phylogenetics and Phylogeography (BPP; Yang and Rannala 2010). The lat- 
ter, has recently been shown to outperform other species delimitation methods under a variety of scenarios (Camargo et al. 2012). In spite of a high degree of morphologi$\mathrm{cal}$ and chemical variation within this species complex, most of the candidate species identified in this study were morphologically and/or chemically polymorphic, and diagnostic morphological/chemical characters were not identified for the majority of the independent species-level lineages (Leavitt et al. 2011a). Recently, additional data, including broader geographic sampling and three additional genetic markers, provide additional support that the candidate species identified in Leavitt et al. (2011a) represent species-level lineages (Leavitt et al. 2013).

While morphological and chemical character differences have traditionally served as proxies for identifying reproductively isolated groups, multilocus coalescent-based species delimitation methods can provide a more direct assessment of gene flow and independent lineage status through genetic analysis. Coalescent-based methods can provide a more direct and replicable approach for assessing hypotheses of evolutionary independence, regardless of whether putative lineages differ in potentially subjective phenotypic character systems (Fujita et al. 2012). Character evolution in lichens is still poorly understood, leading to potentially confounding morphological/chemical taxonomic features (e.g. Leavitt et al. 2011b; Leavitt et al. 2011c; Pino-Bodas et al. 2011; Pérez-Ortega et al. 2012; PinoBodas et al. 2012). While we are strong advocates for the application of independent data types (i.e. ecology, geography, morphology, genetics, and chemistry) in developing an integrative taxonomy, there is an increasing need to formally recognize the existence of phenotypically cryptic species-level lineages in lichen-forming fungi (Hibbett et al. 2011).

In this paper we use support from the coalescent-based species delimitation method implemented in the program BPP (Yang and Rannala 2010) as the diagnostic feature distinguishing new species from other taxa. While in practice, most modern species descriptions include a character-based diagnosis, it has been argued that coalescent-based diagnosis serve the same purpose as a standard diagnosis when the species in question is not diagnosable on the basis of morphology alone (Leache and Fujita 2010; Fujita and Leache 2011; Fujita et al. 2012).

Rhizoplaca melanophthalma s.l. is frequently used in air quality bio-monitoring studies (Dillman 1996; Ugur et al. 2004), and differences in pollution accumulation patterns among closely related species have not been tested. In addition, $R$. melanophthalma s.l. has been shown to have pharmaceutical potential for treating drug genotoxicity in human blood (Geyikoglu et al. 2007). Therefore, accurate specimen identification may have important implications for bio-monitoring and pharmaceutical research using $R$. melanophthalma s.l. Furthermore, several lineages within the $R$. melanophthalma species-complex are broadly distributed (Leavitt et al. 2013), and these may potentially serve as valuable groups for assessing dispersal capacity and landscape-level genetics in response to changing climatic conditions, assuming accurate specimen identification. Given the overall importance of accurate specimen identification, including phenotypically cryptic lineages, the objectives of this study are to (1) formally describe five new species within this group and (2) provide a reference DNA sequence database using the ITS marker as a DNA barcode for identifying species within this complex. 


\section{Methods}

\section{Candidate species and taxon sampling}

Using multilocus sequence data generated from Rhizoplaca specimens collected throughout the Intermountain region of western North America, Leavitt et al. (2011a) circumscribed six candidate species, 'C2', 'C3', 'C4a', 'C4b', 'C4c', and 'C4d', within $R$. melanophthalma s.l. Based on initial sampling, these six species-level lineages were strongly supported by a variety of operational criteria for species delimitation (Leavitt et al. 2011a). Furthermore, many of the candidate species within $R$. melanophthalma s.l. were shown to occur sympatrically with strong evidence of reproductive isolation among lineages (Leavitt et al. 2011a), and thus de facto species status. However, these candidate species were not formally described due to the limited geographical sampling. Increased geographic sampling, including collections from Antarctica, Central Asia, Europe, and North and South America, along with additional genetic markers corroborate the previously recognized candidate species (Leavitt et al. 2013).

\section{Data analysis}

In this study, we used the ITS alignment and phylogeny reported in Leavitt et al. (2013) (Fig. 2A; supplementary file 1; TreeBase ID 13903). This data consisted of 228 sequences and 524 aligned nucleotide position characters. A full description of multiple sequence alignment and phylogenetic reconstruction methods is given in Leavitt et al. (2013). In short, the multiple sequence alignment was performed using the program MAFFT v6 (Katoh et al. 2005; Katoh and Toh 2008), and phylogenetic relationships were estimated using maximum likelihood using the program RAxML v7.2.8 (Stamatakis 2006; Stamatakis et al. 2008).

In the present study, we calculated pairwise distances to characterize both intraand interspecific variation within and among candidate species-level lineages. Pairwise distances can be viewed as a rough measure for the overall sequence divergence (DelPrado et al. 2010). Average genetic distances were computed using PAUP* (Swofford 2002) based on pairwise comparisons of all sequences within each candidate species individually, overall intraspecific distances from all species, and pairwise interspecific distances. Pairwise distances between different haplotypes were reported as the number of nucleotide substitutions per site $(\mathrm{s} / \mathrm{s})$.

The Barcode of Life Data Systems (BOLD; Ratnasingham and Hebert 2007) provides an informatics workbench aiding the acquisition, storage, analysis, and application of DNA barcode data, including a BLAST-based identification tool for fungi using the ITS region. Data from the candidate species circumscribed in Leavitt et al. (2011a), including ITS sequences, electropherograms, and collection information, were submitted to the BOLD database, project name 'Rhizoplaca melanophthalma- 
A

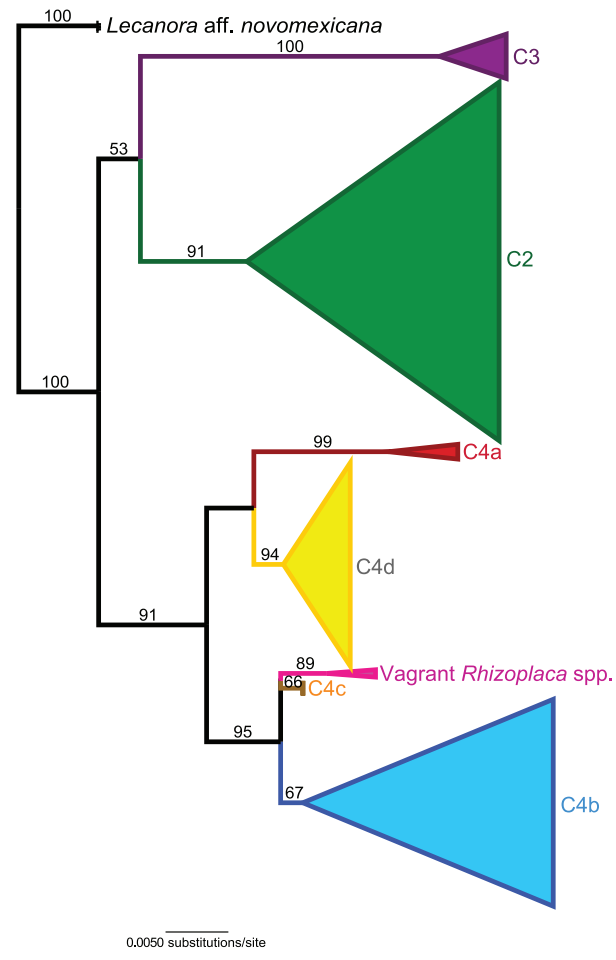

B

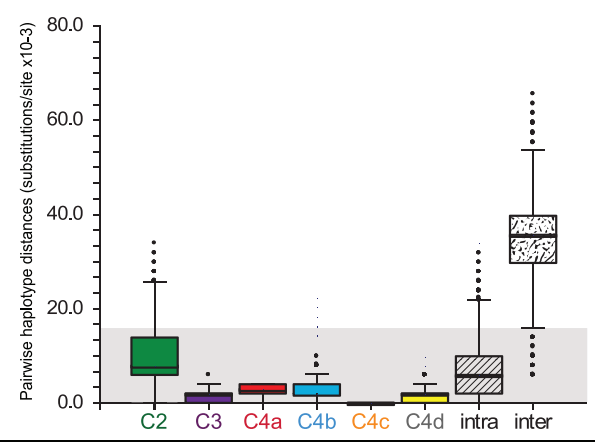

C

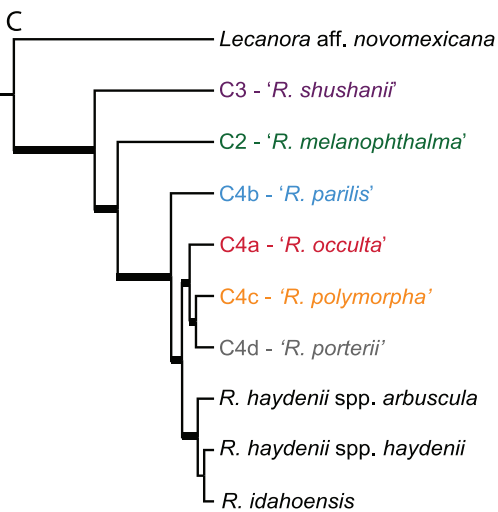

Figure 2. A Cartoon representation of the maximum likelihood ITS topology obtained from 240 Rhizoplaca melanophthalma sensu lato specimens in Leavitt et al. (in review). Values at each node indicate nonparametric-bootstrap support; only support values $>50 \%$ are indicated B Box plots of ITS genetic distances within each new species, all intraspecific distances, and all interspecific distances. In each box plot, the box shows the interquartile range (IQR) of the data. The IQR is defined as the difference between the 75th percentile and the 25 th percentile. The solid and dotted line through the box represent the median and the average length, respectively; and $\mathbf{C}$ The coalescent-based species-tree for the Rhizoplaca melanophthalma species-complex estimated from five genetic markers (ITS, IGS, group I intron, $\beta$-tubulin, and MCM7 loci) in Leavitt et al. 2011a.

species complex'. This custom database includes collections form the western USA representing the six previously recognized candidate species.

We assessed the utility of the ITS region for BLAST-based specimen identification in the $R$. melanophthalma group by conducting searches of the newly reported ITS sequences in Leavitt et al. (2013) against the custom BOLD database. The queried sequences were generated from $R$. melanophthalma s.l. specimens from Antarctica, Austria, Chile, China, the Czech Republic, Iran, Kazakhstan, Kyrgyzstan, Russia, Spain, Switzerland, and additional specimens from the United States of America (supplementary file 1). Top species matches obtained from the BLAST searches against the BOLD database for each specimen were recorded and compared with results from a standard, tree-based method 
to address accuracy of identification in a thoroughly sampled phylogeny. Species were scored as successfully discriminated if the samples were recovered within monophyletic clades in the ML analysis corresponding to candidate species and if top species matches for each new sequence obtained from the BLAST searches against the BOLD database corresponded to the monophyletic clade where it was recovered.

The marginal posterior probability of speciation (speciation probability) was estimated in Leavitt et al. (2013) from multi-locus sequence data using the program BPP v2.1 (Yang and Rannala, 2010). This method accommodates the species phylogeny as well as lineage sorting due to ancestral polymorphism. BPP has recently been shown to outperform other coalescent-based species delimitation methods, with robust performance using a modest number of genetic markers (Camargo et al., 2012). Full details are reported in Leavitt et al. (2013) and summarized only briefly here. The multi-locus species tree, representing the six candidate species, was used as the fully resolved guide tree. Because the prior distribution of $\theta$ and $\tau_{0}$ can result in strong support for models containing more species (Leaché \& Fujita, 2010), Leavitt et al. (2013) explored three combinations of priors, including a moderate and conservative combination. The most conservative combinations of priors favors fewer species by assuming large ancestral population sizes, and relatively shallow divergences among species. The moderately conservative set of priors assumed intermediate ancestral population sizes, and relatively shallow divergences among species. High speciation probabilities ( $S P \geq 0.95)$ were estimated at all nodes using both the default prior gamma distributions for $\theta$ and $\tau_{0}$ and a more moderate combination of these priors, with the exception of the split between the two vagrant species ( $R$. haydenii and $R$. idahoensis). Under the most conservative combination of priors for $\theta$ and $\tau_{0}$, speciation probabilities match those supported using default priors, with the exception of lower probabilities for a split between 'C4d' and 'C4c' $(\mathrm{SP}<0.50)$.

\section{Results}

For each candidate species, the pairwise distances among the different ITS haplotypes were estimated and the distribution of distances plotted (Fig. 2B). Intraspecific genetic distances in candidate species-level lineages 'C3', 'C4a', 'C4b', 'C4c' and 'C4d' were less than or equal to the lowest interspecific pairwise comparison values ( 0.006 substitutions/site), with the exception of outlier values in 'C4b' and 'C4d' (Fig. 2B). The outlier values within clade ' $\mathrm{C} 4 \mathrm{~b}$ ' were based on comparisons from two sequences retrieved from GenBank (EF095278 and EF095287). We were unable to verify the quality of these sequences. Within candidate lineage ' $\mathrm{C} 2$ ', intraspecific values largely fell below the lower quartile of interspecific pairwise comparison values (Fig. 2B), although there was substantial overlap between intra- and interspecific genetic distance values. Mean distance values, standard deviations and the range of intraspecific distances within the six candidate species are reported in Table 1. 
Table I. Mean genetic distance values (given as number of nucleotide substitution per site) and range of intraspecific distances for the Rhizoplaca melanophthalma species-complex. Numbers within parentheses indicate the number of sampled individuals/lineage; and values following mean genetic distance represent standard deviations.

\begin{tabular}{l|c|c}
\hline Species/Clade & Mean & range \\
\hline$R$. melanophthalma 'C2' (98) & $0.009 \pm 0.006$ & $0.0-0.034$ \\
\hline$R$. occulta 'C4a' (5) & $0.003 \pm 0.001$ & $0.0-0.004$ \\
\hline$R$. parilis 'C4b' (56) & $0.003 \pm 0.004$ & $0.0-0.022$ \\
\hline$R$. polymorpha 'C4c' (6) & $0.0 \pm 0$ & $0.0-0.0$ \\
\hline$R$. porterii 'C4d' (57) & $0.002 \pm 0.002$ & $0.0-0.010$ \\
\hline$R$. shushanii 'C3'(13) & $0.001 \pm 0.002$ & $0.0-0.006$ \\
\hline Intraspecific & $0.007 \pm 0.006$ & $0.0-0.034$ \\
\hline Interspecific & $0.033 \pm 0.009$ & $0.006-0.066$ \\
\hline
\end{tabular}

In all BLAST-based searches against the BOLD database, the sequences with the highest overall similarity to the query sequence were also recovered in the corresponding monophyletic clade.

\section{The species}

Rhizoplaca melanophthalma (DC.) Leuckert \& Poelt Nova Hedwigia 28: 72 (1977) MycoBank no. MB 343580

http://species-id.net/wiki/Rhizoplaca_melanophthalma

Basionym. Lichen melanophthalma Ramond in Lamarck \& de Candolle, Fl. Franc. Ed. 3.2:377 (1805).

Epitype. Spain, Teruel, Noguera de Albarracín, carretera A-1521 hacia Orihuela del Tremedal, antes de la Peña del Castillo, pista a "Ruta Laguna", "Peña Aguada", 30TXK16815, $1590 \mathrm{~m}$ alt., on quartzite in a Quercus pyrenaica and Pinus sylvestris forest, 04 October 2010, M. Vivas \& J. Rico, Vivas 94, MAF -Lich 16805 (Epitype: MAF-Lich). We were unable to obtain fresh material from the Pic du Midi de Bigorre in the French Pyrenees (location of original type collection of $R$. melanophthalma). In order to fix the application of the name, we selected a specimen from Teruel, Spain (MAF-Lich 16805) as the epitype. The epitype shares an identical ITS haplotype with specimens collected in Chile, China, Spain, Switzerland, and the USA, and thus appropriately represents the cosmopolitan distribution of $R$. melanophthalma s.s. The ITS sequence of the epitype is deposited in GenBank under accession no. JX948232.

Description. A morphological description can be found in Leuckert et al. (1977) and Ryan (2001). Rhizoplaca melanophthalma consists of specimens recovered within 'clade II' in Leavitt et al. (2011a), which is supported as a lineage distinct from all other populations according to coalescent-based genetic analysis of multiple genetic loci. The mean genetic distances among ITS haplotypes was estimated to be $0.009 \pm 0.006$. 
Chemistry - Usnic acid (major); usually with psoromic (major), constipatic (minor), dehydroconstipatic (minor), dehydroprotocetraric (minor), and 2'-O-demethylsubpsoromic (minor or trace) acids; occasionally with subpsoromic (minor) and 2'-Odemethylpsoromic (minor) acids.

Reference phylogeny. Supplementary file 2 (terminal label: '6604') \& Leavitt et al. 2011a (Fig. 5, 'clade II').

Reference sequence. GenBank no. JX948232.

Phylogenetic notes: Strongly supported as monophyletic lineage in both concatenated multilocus gene tree (ML bootstrap $=95 \%$ : posterior probability $=1.0)$ and the ITS gene topology (ML bootstrap $=91 \%$, this study); and strong speciation probability inferred from multiple loci (BPP speciation probability $=1.0$ ).

Ecology and distribution. In its narrower circumscription, this taxon is known from Antarctica, Asia (including Central Asia and China), Europe, North and South America. The species has also been recorded from alpine areas in the tropics. However, additional studies are required to verify the identity of these populations. It typically occurs on exposed calcium-poor rock (e.g. basalt, granite, schist), but sometimes on calcium rich sandstone and limestone. It ranges in distribution from arid lowland woodlands into upper montane coniferous forests and the lower portions of the alpine tundra. Specimens examined. See supplementary file 1 .

\section{Rhizoplaca occulta S. Leavitt, F. Fernández-Mendoza, Lumbsch, Sohrabi \& L. St. Clair, sp. nov. \\ MycoBank no. MB 803475 \\ http://species-id.net/wiki/Rhizoplaca_occulta}

Type. USA, Nevada, White Pine County, on Cave Mountain, north of antenna site, Humboldt-Toiyabe National Forest, $39.1734^{\circ} \mathrm{N},-114.6130^{\circ} \mathrm{W}$, on basalt, $3150 \mathrm{~m}$ alt., July 2010, S. D. Leavitt \& Larry L. St. Clair BRY-C55076 (holotype BRY).

Description. Consists of specimens recovered within 'clade IVa' in Leavitt et al. (2011a), which is supported as a lineage distinct from all other populations according to coalescent-based genetic analysis of multiple genetic loci. This species is morphologically variable. While some individuals are morphologically similar to $R$. melanophthal$m a$ sensu stricto, vagrant forms, including $R$. cerebriformis ined. and $R$. subidahoensis ined. which have been suggested to be distinct species based on morphology (Arup and Grube 2000; Figs. $7 \& 9$ ), also belong within this species. The mean genetic distance among ITS haplotypes was estimated to be $0.003 \pm 0.001$.

Chemistry - Usnic (major), constipatic (minor), dehydroconstipatic (minor), 2'-Odemethylpsoromic (minor), and 2'-O-demethylsubpsoromic (minor or trace) acids; usually with psoromic acid (major); and occasionally with dehydroprotocetraric acid (minor).

Reference phylogeny. Leavitt et al. 2011a (Fig. 5, 'clade IVa').

Reference sequences. GenBank Nos. HM577307 (ITS), HM577081 (IGS), HM577210 (group I intron), HM577441 (MCM7), and HM576952 ( $\beta$-tubulin). 
Phylogenetic notes: Strongly supported as monophyletic lineage in both concatenated multilocus gene tree (ML bootstrap $=100 \%$ : posterior probability $=1.0$ ) and the ITS gene topology (ML bootstrap $=99 \%$, this study); and strong speciation probability inferred from multiple loci (BPP speciation probability $\geq 0.98$ ). $R$. occulta belongs to a closely related, and well-supported, monophyletic lineage including $R$. paralis, $R$. polymorpha, $R$. porterii, and the obligatory vagrant species $R$. haydenii and R. idahoensis.

Ecology and distribution. Growing usually on exposed calcium-poor rock (e.g. basalt, granite, schist) in pinyon-juniper woodlands but also occurs free on soil. So far known only from collections in western North America. $R$. occulta included a total of five individuals from Idaho (3 individuals), Nevada (1), and Utah (1), USA, and included GenBank accessions identified as $R$. cerebriformis ined. (AF159942) and $R$. subidahoensis ined. (AF159944).

Etymology. The name is derived from the Latin "occultus," meaning hidden, and refers to the fact that this species was hidden within the phenotypically circumscribed taxon Rhizoplaca melanophthalma sensu lato.

Specimens examined. See supplementary file 1.

\author{
Rhizoplaca parilis S. Leavitt, F. Fernández-Mendoza, Lumbsch, Sohrabi \& L. St. \\ Clair, sp. nov. \\ MycoBank no. MB 803476 \\ http://species-id.net/wiki/Rhizoplaca_parilis
}

Type. USA, Utah, Sevier County, Thousand Lakes Mountain, north of 'Flat Top', $38.5111^{\circ} \mathrm{N},-111.4732^{\circ} \mathrm{W}$, on basalt, $2875 \mathrm{~m}$ alt., October 1997, Lyndon D. Porter BRY-C55077 (holotype BRY).

Description. Morphologically similar to $R$. melanophthalma sensu stricto, but consists of specimens recovered within 'clade IVb' in Leavitt et al. (2011a), which is supported as a lineage distinct from all other populations according to coalescentbased genetic analysis of multiple genetic loci. Within the $R$. melanophthalma speciescomplex, the occurrence of orsellinic, lecanoric, and gyrophoric acids appear to be restricted to $R$. parilis. However, the occurrence of these compounds varies widely within this species, with the proportional occurrence of each compound ranging between $0.43-0.64$ (Leavitt et al. 2011a). The mean genetic distance among ITS haplotypes was estimated to be $0.003 \pm 0.004$.

Chemistry - Usnic (major) and psoromic (major) acids; usually with constipatic (minor), dehydroconstipatic (minor), dehydroprotocetraric (minor), lecanoric (major), orsellinic (minor), and subpsoromic (minor) acids; occasionally with gyrophoric (trace), 2'-O-demethylsubpsoromic (minor or trace) and 2'-O-demethylpsoromic (minor) acids.

Reference phylogeny. Leavitt et al. 2011a (Fig. 5, 'clade IVb'). 
Reference sequences. GenBank Nos. HM577308 (ITS), HM577082 (IGS), HM577211 (group I intron), HM577442 (MCM7), and HM576953 ( $\beta$-tubulin)

Phylogenetic notes: Strong to moderate support as monophyletic lineage in both concatenated multilocus gene tree (ML bootstrap $=83 \%$ : posterior probability $=0.93$ ), and with weak statistical support in the ITS gene topology (ML bootstrap $=67 \%$, this study); and strong speciation probability inferred from multiple loci (BPP speciation probability $=1.0)$. $R$. parilis belongs to a closely related, and well-supported, monophyletic lineage including $R$. occultum, $R$. polymorpha, $R$. porterii, and the obligatory vagrant species $R$. haydenii and $R$. idahoensis.

Ecology and distribution. This species usually occurs on exposed calcium-poor rock (e.g. basalt, granite, schist), but sometimes on calcium rich sandstone and limestone. Its habitat ranges from pinyon-juniper woodlands to montane coniferous forests and the lower portions of alpine tundra. This taxon is currently known from Asia (including Central Asia and China), Europe, and North and South America

Etymology. The specific epithet is chosen from the Latin parilis, meaning equivalent, like, or similar, in reference to the morphological similarity between the new species and the other species within the $R$. melanophthalma species-complex.

Specimens examined. See supplementary file 1.

Rhizoplaca polymorpha S. Leavitt, F. Fernández-Mendoza, Lumbsch, Sohrabi \& L. St. Clair, sp. nov.

MycoBank no. MB 803477

http://species-id.net/wiki/Rhizoplaca_polymorpha

Type. USA, Idaho, Owyhee County, $43.3202^{\circ} \mathrm{N},-116.9795^{\circ} \mathrm{W}, 1291 \mathrm{~m}$ alt., 04 July 2008, S. D. Leavitt, H. C. Leavitt \& J.H. Leavitt BRY-C55093 (holotype BRY).

Description. Rhizoplaca polymorpha consists of specimens recovered within 'clade IVc' in Leavitt et al. (2011a), which is supported as a lineage distinct from all other populations according to coalescent-based genetic analysis of multiple genetic loci. This species is morphologically quite variable. While some individuals are morphologically similar to $R$. melanophthalma sensu stricto, vagrant forms partly embedded in badland soils in western Idaho also belong within this species. The mean genetic distance among ITS haplotypes was estimated to be $0.0 \pm 0$.

Chemistry - Usnic (major), constipatic (minor), dehydroconstipatic (minor), 2'-Odemethylsubpsoromic (minor or trace) and 2'-O-demethylpsoromic (minor) acids; occasionally with dehydroprotocetraric (minor) and psoromic acid (major).

Reference phylogeny. Leavitt et al. 2011a (Fig. 5, 'clade IVc').

Reference sequences. GenBank Nos. HM577324 (ITS), HM577097 (IGS), HM577227 (group I intron), HM577458 (MCM7), and HM576968 ( $\beta$-tubulin).

Phylogenetic notes: Strongly supported as monophyletic lineage in both concatenated multilocus gene tree (ML bootstrap $=82 \%$ : posterior probability $=1.0)$, and 
weak statistical support in the ITS gene topology (ML bootstrap $=66 \%$, this study); and strong speciation probability inferred from multiple loci (BPP speciation probability $\geq 0.97)$. $R$. polymorpha belongs to a closely related, and well-supported, monophyletic lineage including $R$. occulta, $R$. parilis, $R$. porterii, and the obligatory vagrant species $R$. haydenii and $R$. idahoensis.

Ecology and distribution. Currently only known from collections in western North America. Its habitat includes pinyon-juniper woodlands and montane coniferous forests, but unattached forms are also known from the McBride Creek Badlands in Western Idaho.

Etymology. The specific epithet was selected based on the morphologically polymorphic forms within this species, including both umbilicate and vagrant forms.

Specimens examined. See supplementary file 1.

\author{
Rhizoplaca porterii S. Leavitt, F. Fernández-Mendoza, Lumbsch, Sohrabi \& L. St. \\ Clair, sp. nov. \\ MycoBank no. MB 803478 \\ http://species-id.net/wiki/Rhizoplaca_porterii
}

Type. USA, Utah, Wayne County, Thousand Lakes Mountain, vicinity of 'Flat Top', near summit, $38.4432^{\circ} \mathrm{N},-111.4703^{\circ} \mathrm{W}$, on basalt, $3400 \mathrm{~m}$ alt., October 1997, Lyndon D. Porter BRY-C55096 (holotype BRY).

Description. Morphologically similar to $R$. melanophthalma sensu stricto, but consists of specimens recovered within 'clade IVd' in Leavitt et al. (2011a), which is supported as a lineage distinct from all other populations according to coalescent-based genetic analysis of multiple genetic loci. This species is also characterized by the absence of a group I intron in the nuclear SSU rDNA at the 1516 position (Gutiérrez et al. 2007), which is present in all other species within the $R$. melanophthalma species-complex. The mean genetic distances among ITS haplotypes was estimated to be $0.002 \pm 0.002$.

Chemistry - Usnic acid (major); usually with psoromic (major), constipatic (minor), dehydroconstipatic (minor), dehydroprotocetraric (minor), subpsoromic (minor), demethylpsoromic (minor), and 2'-O-demethylsubpsoromic (minor or trace) acids.

Reference phylogeny. Leavitt et al. 2011a (Fig. 5, 'clade IVd').

Reference sequences. GenBank Nos. HM577327 (ITS), HM57710 (IGS), HM577461 (MCM7), and HM576971 ( $\beta$-tubulin).

Phylogenetic notes: A monophyletic lineage in both concatenated multilocus gene tree with weak statistical support (ML bootstrap $<50 \%$; posterior probability $<0.5$ ), and with strong statistical support in the ITS gene topology (ML bootstrap = $94 \%$, this study); and strong speciation probability inferred from multiple loci (BPP speciation probability $\geq 0.97$ ). $R$. porterii belongs to a closely related, and well-supported, monophyletic lineage including $R$. occulta, $R$. parilis, $R$. porterii, and the obligatory vagrant species $R$. haydenii and $R$. idahoensis. 
Ecology and distribution. This species usually occurs on exposed calcium-poor rock (e.g. basalt, granite, schist), but sometimes on calcium rich sandstone and limestone. Its habitat ranges from pinyon-juniper woodland into montane coniferous forests and lower alpine tundra. This taxon is currently known only from the western USA (Idaho and Utah).

Etymology. The new taxon is named in honor of Dr. Lyndon D. Porter, whose research on Rhizoplaca melanophthalma proved invaluable to the present work.

Specimens examined. See supplementary file 1.

\author{
Rhizoplaca shushanii S. Leavitt, F. Fernández-Mendoza, Lumbsch, Sohrabi \& L. \\ St. Clair, sp. nov. \\ MycoBank no. MB 803479 \\ http://species-id.net/wiki/Rhizoplaca_shushanii
}

Type. USA, Utah, Wayne County, Thousand Lakes Mountain, vicinity of 'Flat Top', near summit, $38.4366^{\circ} \mathrm{N},-111.4677^{\circ} \mathrm{W}$, on basalt, $3270 \mathrm{~m}$ alt., October 1997 , Lyndon D. Porter BRY-C55061 (holotype BRY).

Description. Morphologically similar to $R$. melanophthalma sensu stricto, but consists of specimens recovered within 'clade III' in Leavitt et al. (2011a), which is supported as a lineage distinct from all other populations according to coalescentbased genetic analysis of multiple genetic loci. The mean genetic distances among ITS haplotypes was estimated to be $0.001 \pm 0.002$.

Chemistry - Usnic (major), psoromic (major), subpsoromic (minor), and 2'-Odemethylsubpsoromic (minor or trace) acids; usually with constipatic (minor) and 2'-O-demethylpsoromic (minor) acids; and occasionally with dehydroconstipatic (minor) and dehydroprotocetraric (minor) acids.

Reference phylogeny. Leavitt et al. 2011a (Fig. 5, 'clade III').

Reference sequences. GenBank Nos. HM577282 (ITS), HM577058 (IGS), HM577187 (group I intron), HM577416 (MCM7), and HM576927 ( $\beta$-tubulin).

Phylogenetic notes: A monophyletic lineage in both concatenated multilocus gene tree with strong statistical support (ML bootstrap $=100 \%$; posterior probability 1.0 ), and with strong statistical support in the ITS gene topology (ML bootstrap = $100 \%$, this study); and high speciation probability inferred from multiple loci (BPP speciation probability $=1.0$ ).

Ecology and distribution. Found growing only on sun-exposed basalt boulders in subalpine meadows in southwestern USA. Currently known only from subalpine habitats on the Aquarius Plateau in southern Utah, USA.

Etymology. The new taxon is named in honor of the late Dr. Sam Shushan, a pioneer in western North American lichenology.

Specimens examined. See supplementary file 1. 


\section{Discussion}

In this study we described five new species within Rhizoplaca melanophthalma s.l. Our results indicate that a molecular-based approach for specimen identification in the common lichen-forming $R$. melanophthalma species-complex can effectively assign individuals from cosmopolitan populations to previously circumscribed 'candidate' species (Leavitt et al. 2011a; Leavitt et al. 2013). Molecular data indicate that the genus Lecanora, as currently circumscribed, is not monophyletic (Arup and Grube 1998; 2000; Lumbsch 2002; Grube et al. 2004). The Rhizoplaca melanophthalma speciescomplex clearly falls outside of the core group of Lecanora sensu stricto (including the type species L. allophana; see Brodo and Vitikainen 1984), and we choose to describe the new species within the heterogeneous, and also non-monophyletic, genus Rhizoplaca, pending future taxonomic revisions.

In spite of the limitations in delimiting taxa using molecular data, the effective use of genetic data appears to be essential to appropriately and practically identify natural groups in some phenotypically cryptic lichen-forming fungal lineages (Divakar et al. 2010b; Leavitt et al. 2011b; Leavitt et al. 2011c; Molina et al. 2011b; Pino-Bodas et al. 2011; Pino-Bodas et al. 2012), including $R$. melanophthalma s.l. This does not preclude the fact that additional studies investigating morphological and chemical characters may potentially identify independent characters, or combinations of characters, supporting species circumscribed using molecular data. In fact, under the general lineage species concept (GLC; de Queiroz 1998, 1999, 2007), more independent properties associated with putative species boundaries are associated with a higher degree of corroboration, resulting in a truly integrative approach to species discovery. However, robust species delimitations using molecular data in phenotypically cryptic species can provide working hypotheses about what constitutes separately evolving metapopulation lineages (de Queiroz 1998; 1999; Mayden 1999; de Queiroz 2007; Fujita et al. 2012). DNA barcoding provides an objective approach for specimen identification within these taxonomically difficult groups.

Within the Rhizoplaca melanophthalma species-complex, DNA barcoding can be performed in a variety of ecological, bio-monitoring and population genetic studies in order to quickly sort specimens into genetically divergent groups. In $R$. melanophthalma s.l., this barcode application for specimen identification may provide a valuable framework for assessing biogeographic patterns, bio-monitoring research, and prove to be an important tool in making critical conservation-related decisions. The application of molecular-based identification could also be used as a way for both specialists and non-specialists alike to discriminate species that are otherwise difficult to identify, making specimen identification more accessible and more accurate at the same time. In spite of the progress in recognizing independent species-level lineages within $R$. melanophthalma s.l., high intraspecific distances within $R$. melanophthalma sensu stricto, suggest additional species-level lineages may potentially be hidden within this lineage. In order to address this question, we are currently developing novel genetic markers (i.e. microsatellites) specific for this group in order to assess population structure and gene flow within this broadly distributed species. 
Using ITS sequence data, specimens within the Rhizoplaca melanophthalma species group can be identified by means of DNA barcoding using the publicly available database in BOLD (http://www.boldsystems.org/). Based on our broad intercontinental sampling, it appears that Rhizoplaca melanophthalma s.l. specimens can be accurately identified to species using the BLAST-based identification tool for fungi in BOLD. This provides an objective approach for a broad array of researchers to accurately identify species within this group using ITS sequence data from their collections, regardless of their level of taxonomic expertise.

Although in some cases the ITS region has been shown to be effective for molecular identification using DNA barcoding (Kelly et al. 2011; Schoch et al. 2012), including species within the Rhizoplaca melanophthalma species-complex, the reliance on a single locus for inferring relationships and circumscribing species is problematic because the history of a single gene might not be representative of the organismal history. Within the $R$. melanophthalma species-complex relationships among species-level lineages are largely unsupported in the ITS topology (Fig. 2A) and differ greatly from the coalescence-based species tree estimated from multilocus sequence data (Fig. 2C; Leavitt et al. 2011 a; Leavitt et al. 2013). Additionally, genealogical concordance among independent genetic markers can provide strong evidence that distinct clades represent reproductively isolated lineages among well-separated groups (Dettman et al. 2003; Pringle et al. 2005). Although different datasets and operational criteria may give conflicting or ambiguous results due to the multiple evolutionary processes associated with speciation, the use of multilocus sequence data and multiple empirical methods are known to establish robust species boundaries in many lichen-forming fungal lineages (reviewed in Lumbsch and Leavitt 2011). Within the $R$. melanophthalma species-complex, the majority of candidate species showed high levels of genealogical concordance among three ribosomal and two protein-coding markers (Leavitt et al. 2011a). The coalescentbased species delimitation method BPP (Yang and Rannala 2010) also supported the distinctness of all new Rhizoplaca species described here (Leavitt et al. 2013) and, under a variety of scenarios, has been shown to be among the most accurate coalescent-based species delimitation methods (Camargo et al. 2012).

While in some cases data have supported the taxonomic use of secondary metabolic characters for delimiting lichen taxa (Tehler and Kallersjo 2001; Blanco et al. 2004; Schmitt and Lumbsch 2004; Molina et al. 2011a), other studies found no correlation between chemotypes and lineages identified using molecular phylogenetic reconstructions (Articus et al. 2002; Buschbom and Mueller 2006; Divakar et al. 2006; Nelsen and Gargas 2009; Velmala et al. 2009; Myllys et al. 2011). In spite of some general patterns in the distribution of secondary metabolites among species within the Rhizoplaca melanophthalma species-complex, it appears that chemical characters cannot consistently be used to diagnose independent species-level lineages. For example, within this complex the occurrence of orsellinic, lecanoric, and gyrophoric acids appear to be restricted to $R$. parilis. However, the occurrence of these compounds varies widely within this species, with the proportional occurrence of each compound ranging between $0.43-0.64$ (Leavitt et al. 2011a). Additionally, all sampled specimens 
of vagrant Rhizoplaca species only produced usnic acid, although additional morphological differences are required to accurately identify distinct vagrant species. Previous studies have used TLC to characterize lichen secondary metabolic products within Rhizoplaca (McCune 1987; Zhou et al. 2006). However, it appears that within $R$. melanophthalma s.l. some extrolites would be masked by other compounds, or likely found at levels undetectable by TLC; and HPLC has been shown to provide a more sensitive approach for determining secondary metabolite diversity within the $R$. melanophthalma complex (Leavitt et al. 2011a). In spite of the increased sensitivity of HPLC, unambiguous secondary metabolic characters corroborating most of the species within $R$. melanophthalma s.l., including the most genetically divergent clades, were not identified (Leavitt et al. 2011a).

As molecular sequence data become more readily available, they will allow us to better understand the diversity of lichenized fungi. Their use in identifying species will become increasingly important and routinely applied. Other disciplines such as ecology, conservation and physiology will benefit from a more objectively based species circumscription, enabling us to interpret distribution and ecological patterns better and more accurately monitor environmental disturbance and climate change.

\section{Acknowledgements}

We thank Roger Rosentreter, Johnathon Fankhauser, Leigh Johnson, Christopher Jones, Dean Leavitt, Hailey Leavitt, Jackson Leavitt, Lyndon Porter, Monica Proulx, and Peter Ririe for invaluable assistance with this research. This study was supported, in part, by funds from Brigham Young University graduate mentoring and graduate research fellowship awards, the USDA National Forest Service, the Negaunee Foundation and the National Science Foundation (DEB-0949147). PKD thanks to the Ministerio de Ciencia e Innovación, Spain for financial support (CGL2010-21646/BOS, RYC02007-01576). SPO thanks the JAE-Doc program (CSIC) for financial support.

\section{References}

Articus K, Mattsson J-E, Tibell L, Grube M, Wedin M (2002) Ribosomal DNA and $\beta$-tubulin data do not support the separation of the lichens Usnea florida and U. subfloridana as distinct species. Mycological Research 106: 412-418. doi: 10.1017/S0953756202005786

Arup U, Grube M (1998) Molecular systematics of Lecanora subgenus Placodium. The Lichenologist 30: 415-425. doi: 10.1017/S0024282992000410

Arup U, Grube M (2000) Is Rhizoplaca (Lecanorales, lichenized Ascomycota) a monophyletic genus? Canadian Journal of Botany 78: 318-327. doi: 10.1139/b00-006

Begerow D, Nilsson H, Unterseher M, Maier W (2010) Current state and perspectives of fungal DNA barcoding and rapid identification. Applications in Microbiology and Biotechnology 97: 99-108. doi: 10.1007/s00253-010-2585-4 
Blanco O, Crespo A, Divakar PK, Esslinger TL, Hawksworth DL, Lumbsch HT (2004) Melanelixia and Melanohalea, two new genera segregated from Melanelia (Parmeliaceae) based on molecular and morphological data. Mycological Research 108: 873-884. doi: 10.1017/ S0953756204000723

Brodo IM, Vitikainen O (1984) The typification of Lecanora subfusca (L.) Ach., its varieties, and some of its related taxa published before 1850. Mycotaxon 21: 281-298.

Buschbom J, Mueller GM (2006) Testing “species pair” hypotheses: evolutionary processes in the lichen-forming species complex Porpidia flavocoerulescens and Porpidia melinodes. Molecular Biology and Evolution 23: 574-586. doi: 10.1093/molbev/msj063

Camargo A, Morando M, Avila LJ, Sites JW (2012) Species delimitation with ABC and other coalescent-based methods: A test of accuracy with simulations and an empirical example with lizards of the Liolaemus darwinii complex (Squamata: Liolaemidae). Evolution 66: 2834-2849. doi: 10.1111/j.1558-5646.2012.01640.x

Crespo A, Lumbsch HT (2010) Cryptic species in lichen-forming fungi. IMA Fungus 1: 167170. doi: 10.5598/imafungus.2010.01.02.09

Crespo A, Pérez-Ortega S (2009) Cryptic species and species pairs in lichens: a discussion on the relationship between molecular phylogenies and morphological characters. Anales del Jardín Botanico de Madrid 66(S1): 71-81. doi: 10.3989/ajbm.2225

de Queiroz K (1998) The general lineage concept of species, species criteria, and the process of speciation: a conceptual unification and terminological recommendations. In: Howard DJ, Berlocher SH (Eds) Endless forms: Species and speciation. Oxford University Press, New York, 57-75.

de Queiroz K (1999) The general lineage concept of species and the defining properties of the species category. In: Wilson RA (Ed) New interdisciplinary essays. MIT Press, Cambridge, Massachusetts, 49-89.

de Queiroz K (2007) Species Concepts and Species Delimitation. Systematic Biology 56: 879_ 886. doi: 10.1080/10635150701701083

Del-Prado R, Cubas P, Lumbsch HT, Divakar PK, Blanco O, de Paz GA, Molina MC, Crespo A (2010) Genetic distances within and among species in monophyletic lineages of Parmeliaceae (Ascomycota) as a tool for taxon delimitation. Molecular Phylogenetics and Evolution 56: 125-133. doi: 10.1016/j.ympev.2010.04.014

Dettman J, Jacobson D, Taylor J (2003) A multilocus genealogical approach to phylogenetic species recognition in the model eukaryote Neurospora. Evolution 57: 2703-2720. doi: 10.1111/j.0014-3820.2003.tb01514.x

Dillman KL (1996) Use of the lichen Rhizoplaca melanophthalma as a biomonitor in relation to phosphate refineries near Pocatello, Idaho. Environmental Pollution 92: 91-96. doi: 10.1016/0269-7491(95)00084-4

Divakar PK, Crespo A, Blanco O, Lumbsch HT (2006) Phylogenetic significance of morphological characters in the tropical Hypotrachyna clade of parmelioid lichens (Parmeliaceae, Ascomycota). Molecular Phylogenetics and Evolution 40: 448-458. doi: 10.1016/j. ympev.2006.03.024

Divakar PK, Figueras G, Hladun N, Crespo A (2010a) Molecular phylogenetic studies reveal an undescribed species within the North American concept of Melanelixia glabra (Parmeliaceae). Fungal Diversity 42: 47-55. doi: 10.1007/s13225-010-0027-3 
Divakar PK, Lumbsch HT, Ferencova Z, Del Prado R, Crespo A (2010b) Remototrachyna, a newly recognized tropical lineage of lichens in the Hypotrachyna clade (Parmeliaceae, Ascomycota), originated in the Indian subcontinent. American Journal of Botany 97: 579-590. doi: 10.3732/ajb.0900140

Feuerer T, Hawksworth D (2007) Biodiversity of lichens, including a world-wide analysis of checklist data based on Takhtajan's floristic regions. Biodiversity and Conservation 16: 85-98. doi: 10.1007/s10531-006-9142-6

Fujita MK, Leache AD (2011) A coalescent perspective on delimiting and naming species: a reply to Bauer et al. Proceedings of the Royal Society of London B 278: 493-495. doi: 10.1098/rspb.2010.1864

Fujita MK, Leaché AD, Burbrink FT, McGuire JA, Moritz C (2012) Coalescent-based species delimitation in an integrative taxonomy. Trends in Ecology \& Evolution 27: 480-488. doi: $10.1016 /$ j.tree.2012.04.012

Geyikoglu F, Turkez H, Aslan A (2007) The protective roles of some lichen species on colloidal bismuth subcitrate genotoxicity. Toxicology and Industrial Health 23: 487-492. doi: $10.1177 / 0748233708089044$

Grube M, Baloch E, Arup U (2004) A phylogenetic study of the Lecanora rupicola group (Lecanoraceae, Ascomycota). Mycological Research 108: 506-514. doi: 10.1017/ S0953756204009888

Gutiérrez G, Blanco O, Divakar P, Lumbsch H, Crespo A (2007) Patterns of group i intron presence in nuclear SSU rDNA of the lichen family Parmeliaceae. Journal of Molecular Evolution 64: 181-195. doi: 10.1007/s00239-005-0313-y

Hibbett DS, Ohman A, Glotzer D, Nuhn M, Kirk P, Nilsson RH (2011) Progress in molecular and morphological taxon discovery in Fungi and options for formal classification on environmental sequences. Fungal Biology Reviews 25: 38-47. doi: 10.1016/j.fbr.2011.01.001

Kelly LJ, Hollingsworth PM, Coppins BJ, Ellis CJ, Harrold P, Tosh J, Yahr R (2011) DNA barcoding of lichenized fungi demonstrates high identification success in a floristic context. New Phytologist 191: 288-300. doi: 10.1111/j.1469-8137.2011.03677.x

Kiss L (2012) Limits of nuclear ribosomal DNA internal transcribed spacer (ITS) sequences as species barcodes for Fungi. Proceedings of the National Academy of Sciences 109: E1811. doi: 10.1073/pnas.1207143109

Leaché AD, Fujita MK (2010) Bayesian species delimitation in West African forest geckos (Hemidactylus fasciatus). Proceedings of the Royal Society B: Biological Sciences 277: 3071-3077. doi: 10.1098/rspb.2010.0662

Leavitt SD, Fankhauser JD, Leavitt DH, Porter LD, Johnson LA, St. Clair LL (2011a) Complex patterns of speciation in cosmopolitan "rock posy" lichens - Discovering and delimiting cryptic fungal species in the lichen-forming Rhizoplaca melanophthalma species-complex (Lecanoraceae, Ascomycota). Molecular Phylogenetics and Evolution 59: 587-602. doi: 10.1016/j.ympev.2011.03.020

Leavitt SD, Johnson L, St. Clair LL (2011b) Species delimitation and evolution in morphologically and chemically diverse communities of the lichen-forming genus Xanthoparmelia (Parmeliaceae, Ascomycota) in western North America. American Journal of Botany 98: 175-188. doi: 10.3732/ajb.1000230 
Leavitt SD, Johnson LA, Goward T, St. Clair LL (2011c) Species delimitation in taxonomically difficult lichen-forming fungi: An example from morphologically and chemically diverse Xanthoparmelia (Parmeliaceae) in North America. Molecular Phylogenetics and Evolution 60: 317-332. doi: 10.1016/j.ympev.2011.05.012

Leavitt, SD, Fernández-Mendoza, F, Pérez-Ortega, F, Sohrabi M, Divakar PK, Vondrák J, Lumbsch HT, St. Clair LL (2013) Local representation of global diversity in a cosmopolitan lichen-forming fungal species-complex (Rhizoplaca, Ascomycota). Journal of Biogeography. doi: 10.1111/jbi.12118

Leuckert C, Poelt J, Hahnel G (1977) Zur Chemotaxonomie der eurasischen Arten der Flechtengattung rhizoplaca. Nova Hedwigia 28: 71-129

Lücking R, Rivas Plata E, Chaves JL, Umana L, Sipman HJM (2009) How many tropical lichens are there ...really? Bibliotheca Lichenologica 100: 399-418.

Lumbsch HT (2002) How objective are genera in Euascomycetes? Perspectives in Plant Ecology, Evolution and Systematics 5: 91-101. doi: 10.1078/1433-8319-00025

Lumbsch HT, Leavitt SD (2011) Goodbye morphology? A paradigm shift in the delimitation of species in lichenized fungi. Fungal Diversity 50: 59-72. doi: 10.1007/s13225-011-0123-z

Mayden RL (1999) Consilience and a hierarchy of species concepts: Advances towards closure on the species puzzle. The Journal of Nematology 31: 95-116.

McCune B (1987) Distribution of chemotypes of Rhizoplaca in North America. The Bryologist 90: 6-14. doi: 10.2307/3243267

Molina M, Del-Prado R, Divakar P, Sánchez-Mata D, Crespo A (2011a) Another example of cryptic diversity in lichen-forming fungi: the new species Parmelia mayi (Ascomycota: Parmeliaceae). Organisms Diversity \& Evolution 11: 331-342. doi: 10.1007/s13127-0110060-4

Molina M, Divakar PK, Millanes AM, Sanchez E, Del-Prado R, Hawksworth DL, Crespo A (2011b) Parmelia sulcata (Ascomycota: Parmeliaceae), a sympatric monophyletic species complex. The Lichenologist 43: 585-601. doi: 10.1017/S0024282911000521

Myllys L, Velmala S, Holien H, Halonen P, Wang L-S, Goward T (2011) Phylogeny of the genus Bryoria. The Lichenologist 43: 617-638. doi: 10.1017/S0024282911000132

Nelsen MP, Gargas A (2009) Assessing clonality and chemotype monophyly in Thamnolia (Icmadophilaceae). The Bryologist 112: 42-53. doi: 10.1639/0007-2745-112.1.42

Orock EA, Leavitt SD, Fonge BA, St. Clair LL, Lumbsch HT (2012) DNA-based identification of lichen-forming fungi: Can publicly available Sequence databases aid in lichen diversity inventories of Mount Cameroon (West Africa)? The Lichenologist 44: 833-839. doi: 10.1017/S0024282912000424

Pérez-Ortega S, Fernández-Mendoza F, Raggio J, Vivas M, Ascaso C, Sancho LG, Printzen C, de los Ríos A (2012) Extreme phenotypic variation in Cetraria aculeata (lichenized Ascomycota): adaptation or incidental modification? Annals of Botany 109: 1133-1148. doi: $10.1093 / \mathrm{aob} / \mathrm{mcs} 042$

Pino-Bodas R, Burgaz A, Martín M, Lumbsch HT (2011) Phenotypical plasticity and homoplasy complicate species delimitation in the Cladonia gracilis group (Cladoniaceae, Ascomycota). Organisms Diversity \& Evolution 11: 343-355. doi: 10.1007/s13127-011$0062-2$ 
Pino-Bodas R, Burgaz AR, Martin MP, Lumbsch HT (2012) Species delimitations in the Cladonia cariosa group (Cladoniaceae, Ascomycota). The Lichenologist 44: 121-135. doi: 10.1017/S002428291100065X

Pringle A, Baker DM, Platt JL, Wares JP, Latge JP, Taylor JW (2005) Cryptic speciation in the cosmopolitan and clonal human pathogenic fungus Aspergillus fumigatus. Evolution 59: 1886-1899. doi: 10.1111/j.0014-3820.2005.tb01059.x

Printzen C (2010) Lichen systematics: The role of morphological and molecular data to reconstruct phylogenetic relationships. Progress in Botany 71. Springer Berlin Heidelberg, 233-275. doi: 10.1007/978-3-642-02167-1_10

Ratnasingham S, Hebert PDN (2007) BOLD: The Barcode of Life Data System (http:// www.barcodinglife.org). Molecular Ecology Notes 7: 355-364. doi: 10.1111/j.14718286.2007.01678.x

Roe AD, Rice AV, Bromilow SE, Cooke JK, Sperling FAH (2010) Multilocus species identification and fungal DNA barcoding: insights from blue stain fungal symbionts of the mountain pine beetle. Molecular Ecology Resources 10: 946-959. doi: 10.1111/j.17550998.2010.02844.x

Ryan BD (2001) Rhizoplaca. In: Nash III TH, Ryan BD, Gries C, Bungartz F (Eds) Lichen Flora of the Greater Sonoran Desert Region. Lichens Unlimited, Tempe.

Schmitt I, Lumbsch HT (2004) Molecular phylogeny of the Pertusariaceae supports secondary chemistry as an important systematic character set in lichen-forming ascomycetes. Molecular Phylogenetics and Evolution 33: 43-55. doi: 10.1016/j.ympev.2004.04.014

Schmull M, Miadlikowska J, Pelzer M, Stocker-Wörgötter E, Hofstetter V, Fraker E, Hodkinson BP, Reeb V, Kukwa M, Lumbsch HT, Kauff F, Lutzoni F (2011) Phylogenetic affiliations of members of the heterogeneous lichen-forming fungi of the genus Lecidea sensu Zahlbruckner (Lecanoromycetes, Ascomycota). Mycologia 103: 983-1003. doi: 10.3852/10-234

Schoch CL, Seifert KA, Huhndorf S, Robert V, Spouge JL, Levesque CA, Chen W, Bolchacova E, Voigt K, Crous PW, Miller AN, Wingfield MJ, Aime MC, An KD, Bai FY, Barreto RW, Begerow D, Bergeron MJ, Blackwell M, Boekhout T, Bogale M, Boonyuen N, Burgaz AR, Buyck B, Cai L, Cai Q, Cardinali G, Chaverri P, Coppins BJ, Crespo A, Cubas P, Cummings C, Damm U, de Beer ZW, de Hoog GS, Del-Prado R, Dentinger B, Dieguez-Uribeondo J, Divakar PK, Douglas B, Duenas M, Duong TA, Eberhardt U, Edwards JE, Elshahed MS, Fliegerova K, Furtado M, Garcia MA, Ge ZW, Griffith GW, Griffiths K, Groenewald JZ, Groenewald M, Grube M, Gryzenhout M, Guo LD, Hagen F, Hambleton S, Hamelin RC, Hansen K, Harrold P, Heller G, Herrera G, Hirayama K, Hirooka Y, Ho HM, Hoffmann K, Hofstetter V, Hognabba F, Hollingsworth PM, Hong SB, Hosaka K, Houbraken J, Hughes K, Huhtinen S, Hyde KD, James T, Johnson EM, Johnson JE, Johnston PR, Jones EB, Kelly LJ, Kirk PM, Knapp DG, Koljalg U, Kovacs GM, Kurtzman CP, Landvik S, Leavitt SD, Liggenstoffer AS, Liimatainen K, Lombard L, Luangsa-Ard JJ, Lumbsch HT, Maganti H, Maharachchikumbura SS, Martin MP, May TW, McTaggart AR, Methven AS, Meyer W, Moncalvo JM, Mongkolsamrit S, Nagy LG, Nilsson RH, Niskanen T, Nyilasi I, Okada G, Okane I, Olariaga I, Otte J, Papp T, Park D, Petkovits T, Pino-Bodas R, Quaedvlieg W, Raja HA, Redecker D, Rintoul T, Ruibal 
C, Sarmiento-Ramirez JM, Schmitt I, Schussler A, Shearer C, Sotome K, Stefani FO, Stenroos S, Stielow B, Stockinger H, Suetrong S, Suh SO, Sung GH, Suzuki M, Tanaka K, Tedersoo L, Telleria MT, Tretter E, Untereiner WA, Urbina H, Vagvolgyi C, Vialle A, Vu TD, Walther G, Wang QM, Wang Y, Weir BS, Weiss M, White MM, Xu J, Yahr R, Yang ZL, Yurkov A, Zamora JC, Zhang N, Zhuang WY, Schindel D (2012) Nuclear ribosomal internal transcribed spacer (ITS) region as a universal DNA barcode marker for Fungi. Proceedings of the National Academy of Sciences of the United States of America 109: 6241-6246. doi: 10.1073/pnas.1117018109

Seifert KA (2009) Progress towards DNA barcoding of fungi. Molecular Ecology Resources 9: 83-89. doi: 10.1111/j.1755-0998.2009.02635.x

Taylor J, Jacobson D, Kroken S, Kasuga T, Geiser D, Hibbett D, Fisher M (2000) Phylogenetic species recognition and species concepts in fungi. Fungal Genetics and Biology 31: 21-32. doi: 10.1006/fgbi.2000.1228

Tehler A, Källersjö M (2001) Parmeliopsis ambigua and P. hyperopta (Parmeliaceae): species or chemotypes? The Lichenologist 33: 403-408. doi: 10.1006/lich.2001.0342

Ugur A, Özden B, Saç M, Yener G, Altinbaş Ü, Kurucu Y, Bolca M (2004) Lichens and mosses for correlation between trace elements and 210Po in the areas near coal-fired power plant at Yatağan, Turkey. Journal of Radioanalytical and Nuclear Chemistry 259: 87-92. doi: 10.1023/B:JRNC.0000015811.68036.69

Velmala S, Myllys L, Halonen P, Goward T, Ahti T (2009) Molecular data show that Bryoria fremontii and B. tortuosa ( Parmeliaceae) are conspecific. The Lichenologist 41: 231-242. doi:doi: 10.1017/S0024282909008573

Yang Z, Rannala B (2010) Bayesian species delimitation using multilocus sequence data. Proceedings of the National Academy of Sciences 107: 9264-9269. doi: 10.1073/ pnas.0913022107

Zhou Q-M, Guo S-Y, Huang M-R, Wei J-C (2006) A study of the genetic variability of Rhizoplaca chrysoleuca using DNA sequences and secondary metabolic substances. Mycologia 98: 57-67. doi: 10.3852/mycologia.98.1.57 


\section{Appendix I}

Supplementary Table S1. (doi: 10.3897/mycokeys.7.4508.app1) Microsoft Excel Document (xls).

Explanation note: Collection information for all Rhizoplaca melanophthalma sensu lato specimens included in the present study. Modified from Leavitt et al. (2013).

Copyright notice: This dataset is made available under the Open Database License (http://opendatacommons.org/licenses/odbl/1.0/). The Open Database License (ODbL) is a license agreement intended to allow users to freely share, modify, and use this Dataset while maintaining this same freedom for others, provided that the original source and author(s) are credited.

Citation: Leavitt SD, Fernández-Mendoza F, Pérez-Ortega S, Sohrabi M, Divakar PK, Lumbsch TH, St. Clair LLS (2013) DNA barcode identification of lichen-forming fungal species in the Rhizoplaca melanophthalma species-complex (Lecanorales, Lecanoraceae), including five new species. MycoKeys 7: 1-22. doi: 10.3897/mycokeys.7.4508.app1

\section{Appendix 2}

Supplementary Fig S1. (doi: 10.3897/mycokeys.7.4508.app2) File format: Adobe Portable Document Format (pdf).

Explanation note: Maximum likelihood ITS gene tree of the 240 sampled Rhizoplaca melanophthalma sensu lato specimens. Bootstrap support indicated at nodes. Modified from Leavitt et al. (2013).

Copyright notice: This dataset is made available under the Open Database License (http://opendatacommons.org/licenses/odbl/1.0/). The Open Database License (ODbL) is a license agreement intended to allow users to freely share, modify, and use this Dataset while maintaining this same freedom for others, provided that the original source and author(s) are credited.

Citation: Leavitt SD, Fernández-Mendoza F, Pérez-Ortega S, Sohrabi M, Divakar PK, Lumbsch TH, St. Clair LLS (2013) DNA barcode identification of lichen-forming fungal species in the Rhizoplaca melanophthalma species-complex (Lecanorales, Lecanoraceae), including five new species. MycoKeys 7: 1-22. doi: 10.3897/mycokeys.7.4508.app2 